\title{
Development and Validation of New RP-HPLC Method for the Estimation of Alfuzosin Hydrochloride in Bulk and Tablet Dosage Form
}

\author{
Vandana P. Patil", Subhash J. Devdhe, Suwarna H. Kale, Vijay J. Nagmoti, \\ Sadanand D. Kurhade, Yuvraj R. Girbane, Mahesh T. Gaikwad \\ Yash Institute of Pharmacy, Aurangabad, India \\ Email: *vandana2609@gmail.com
}

Received October 6, 2012; revised November 8, 2012; accepted November 15, 2012

\begin{abstract}
A reverse phase high performance liquid chromatographic method (HPLC) has been developed for the estimation of Alfuzosin hydrochloride (ALH) in the pharmaceutical formulation using RP-C18 column. The mobile phase (Tetrahydrofuran, Acetonitrile and buffer $(\mathrm{pH} 3.50)$ was pumped at a flow rate of $1.5 \mathrm{ml} / \mathrm{min}$ in the ratio of 1:20:80 and the eluents were monitored at $254.0 \mathrm{~nm}$. Linearity was obtained in the concentration range of $80-120 \mu \mathrm{g} / \mathrm{mL}$ for ALH. The method was statistically validated and RSD was found to be less than $2 \%$ indicating high degree of accuracy and precision of the proposed HPLC method. Due to its simplicity, rapidness, high precision and accuracy, the proposed HPLC method may be used for determination of Alfuzosin hydrochloride in bulk drugs and in pharmaceutical dosage form.
\end{abstract}

Keywords: Alfuzosin HCl; RP-HPLC; Linearity; Precision; Accuracy; Robustness; Ruggedness

\section{Introduction}

HPLC has gained valuable position in the field of analysis due to ease of performance, specificity, sensitivity and the analysis of sample of complex nature. This technique is commonly used for the quantitative estimation of the drug from their formulation as well as for studying their metabolites and their estimation in the biological fluids. This method offers advantages of estimating the constituents for the multicomponent system without prior separation and even nano quantities can be estimated. Now days, drugs are commonly used clinically and analyst is required to develop suitable method for their analysis.

Alfuzosin hydrochloride (ALH) is chemically known as $\mathrm{N}$-[3-[(4-amino-6, 7-dimethoxy-quinazolin-2-yl)-methyl amino] propyl] tetrahydrofuran-2-carboxamide with an empirical formula of $\mathrm{C} 19 \mathrm{H} 27 \mathrm{~N} 5 \mathrm{O} 4 \cdot \mathrm{HCl}$ (Figure 1) and molecular weight is $425.9 \mathrm{~g} / \mathrm{mol}$. ALH is alphaadrenergic blockers [1] and relaxes the muscles in the prostate and bladder neck, making it easier to urinate. It is used to improve urination in men with benign prostatic hyperplasia [2].

Several analytical methods that have been reported for determination of ALH in biological fluids and pharmaceutical formulation which includes Spectrophotometric

${ }^{*}$ Corresponding author. and Colorimetric methods [3-7], voltammetry method [8], Direct high-performance liquid chromatographic method is also reported for the determination of enantiomers of ALH in plasma [9,10]. RP-HPLC method [11-14], Liquid chromatography-tandem mass spectrometry method [15], validated HPLC and HPTLC stability-indicating methods [16,17] RP-HPLC method for simultaneous estimation of Alfuzosin Hydrochloride and Dutasteride $[18,19]$.

Most of the pharmaceutical industries perform quantitative chemical analysis to ensure that the raw material used and the final product thus obtained meets certain specification and to determine how much of each components are present in the final product. Standard analytical procedure for newer drugs or formulation may not be available in Pharmacopoeias; hence it is essential to develop newer analytical methods which are accurate, precise, specific, linear, simple and rapid.

A fixed dose containing Alfuzosin $\mathrm{HCl}$ is recently<smiles>CCc1cc2nc(N(C)CCCNC(=O)C3CCCO3)nc(N)c2cc1CC</smiles>

Figure 1. Structure of alfuzosin hydrochloride. 
available in market as tablet dosage form and is indicated as adrenergic alpha-antagonists. As per best of author's knowledge, a simple and new RP-HPLC method is limited. So, it was thought of interest to develop a simple, sensitive, accurate and precise RP-HPLC method for analysis of ALH in bulk as well as pharmaceutical formulations.

\section{Experimental}

\subsection{Reagents}

An analytical pure sample of Alfuzosin Hydrochloride was procured as a gift sample from Wockhardt Pvt. Ltd., Aurangabad, Maharashtra, (India). The formulation used was Alfuzosin Hydrochloride tablets containing $10 \mathrm{mg}$ of Alfuzosin Hydrochloride were collected from retailer, Aurangabad, Maharashtra, (India).

All the chemicals used were of analytical grade. Perchloric acid (about 71\% - 73\%) (AR grade), Sodium Hydroxide (AR grade) were purchased from Qualigens Fine Chemicals (Mumbai, India), Acetonitrile (HPLC grade) and Tetrahydrofuran (HPLC grade) were purchased from Merck (Darmstadt, Germany). Milli-Q/HPLC water was used for the preparation of buffer and other aqueous solutions.

\subsection{Instrumentation}

1) Chromatographic separation of Alfuzosin Hydrochloride was performed on Sil C-18 HS (KYA TECH, Japan) column having $250 \times 4.6 \mathrm{~mm}$ ID and $10 \mu \mathrm{m}$ particle size. The Liquid chromatographic system consists of following components: Jasco HPLC model containing PU 2080 Plus Intelligent HPLC pump, Jasco UV 2075 Plus Intelligent UV-Vis Detector and Rheodyne injector (7725i) with $20 \mu$ fixed loop. A Borwin Chromatography software was used for data acquisition and evaluation.

2) The Shimadzu electronic micro balance was used for weighing purpose.

3) An Elder pH meter connected with a PPL CL-51BpH electrode was used to measure the $\mathrm{pH}$ of the aqueous mobile phase.

4) Microsoft Excel 2007 was used to calculate matrices and $p$ values of the regression coefficients.

\subsection{Standard Preparation}

Accurately weigh and transfer about $25.0 \mathrm{mg}$ of Alfuzosin Hydrochloride working standard into a $50 \mathrm{ml}$ volumetric flask, to this add about $30 \mathrm{ml}$ of diluent, Sonicate to dissolve and make up the volume up to the mark with diluent and mix. Pipette $5.0 \mathrm{ml}$ of this solution to a $100 \mathrm{ml}$ volumetric flask and make up the volume up to the mark with diluent and mix [20].

\subsection{Sample Preparation}

Accurately weigh and transfer about $25.0 \mathrm{mg}$ equivalent to Alfuzosin Hydrochloride of sample into a $50 \mathrm{ml}$ volumetric flask, to this add about $30 \mathrm{ml}$ of diluents, sonicate to dissolve and make up the volume up to the mark with diluents and mix. Pipette $5.0 \mathrm{ml}$ of this solution to a $100 \mathrm{ml}$ volumetric flask and make up to the volume up to the mark with diluents and mix.

\subsection{Preparation of Buffer (pH $3.5 \pm 0.05$ )}

Add $5.0 \mathrm{ml}$ of perchloric acid (71\% - 73\%) in $900 \mathrm{ml}$ of water adjust $\mathrm{pH} 3.50 \pm 0.05$ with dilute sodium hydroxide solution and dilute to $1000 \mathrm{ml}$ with water. Mix and filter the solution through $0.45 \mu \mathrm{m}$ or finer porosity membrane and degas.

\subsection{Preparation of Mobile Phase}

Prepare a mixture of Tetrahydrofuran, Acetonitrile and buffer $(\mathrm{pH} 3.5)$ in the ratio of $(1: 20: 80) \mathrm{v} / \mathrm{v} / \mathrm{v}$. Mix and filter the solution through $0.45 \mu \mathrm{m}$ or finer porosity membrane and degas.

\subsection{Preparation of Diluent}

Use mobile phase as a diluent.

\subsection{Preparation of Blank Solution}

Use diluents as a blank.

\subsection{Preparation of Rinsing Solvent}

Prepare a mixture of acetonitrile and water as 40:60 v/v and mix.

\subsection{Method Development}

\subsubsection{Selection of Chromatographic Method}

Proper selection of the method depends upon the nature of the sample, molecular weight and solubility. The drug selected for the present study was polar. Polar compounds can be separated by reverse phase chromatography. Reverse phase chromatographic technique was selected for initial separations from the knowledge of properties of the compound. $\mathrm{C}_{18}$ column was chosen as stationary phase and a mixture of Tetrahydrofuran, Acetonitrile and buffer $(\mathrm{pH} 3.5)$ in the ratio of $(1: 20: 80) \mathrm{v} / \mathrm{v}$ used as mobile phase. Then it was run with different ratios of mobile phase.

\subsubsection{Selection of Column}

Better peak resolution with less tailing was observed Sil C-18 HS (KYA TECH, Japan) column having $250 \times 4.6$ mm ID. 


\subsubsection{Chromatographic Condition}

A reverse phase $\mathrm{C}-18$ column, equilibrated with mobile phase a mixture of Tetrahydrofuran, Acetonitrile and buffer $(\mathrm{pH} 3.5)$ in the ratio of $(1: 20: 80) \mathrm{v} / \mathrm{v} / \mathrm{v}$ was used. The active principle was eluted isocratically and the mobile phase flow rate was maintained at $1.5 \mathrm{ml} / \mathrm{min}$. The effluents were monitored at $254 \mathrm{~nm}$ with the detector. The sample was injected using a $20 \mu$ fixed loop and the total run time was $12 \mathrm{~min}$.

\subsubsection{Procedure}

Separately inject $20 \mu \mathrm{l}$ of the blank solution (one injection), standard preparation in replicate (five injections) and sample preparation (in duplicate) into the chromatograph, record the chromatograms and measure area counts for Alfuzosin Hydrochloride peaks. Figures 2-4 have shown the chromatorgram for Blank, Standard and Sample of Alfuzosin hydrochloride by RP-HPLC method.

\section{Method Validation}

The proposed RP-HPLC method was validated as per ICH guidelines.

\subsection{Stability}

In order to demonstrate the stability of the standard solution of Alfuzosin Hydrochloride during analysis, the solution was stored over a period of $24 \mathrm{hr}$ at room temperature and then analyzed.

\subsection{System Suitability}

A Standard solution of Alfuzosin working standard was

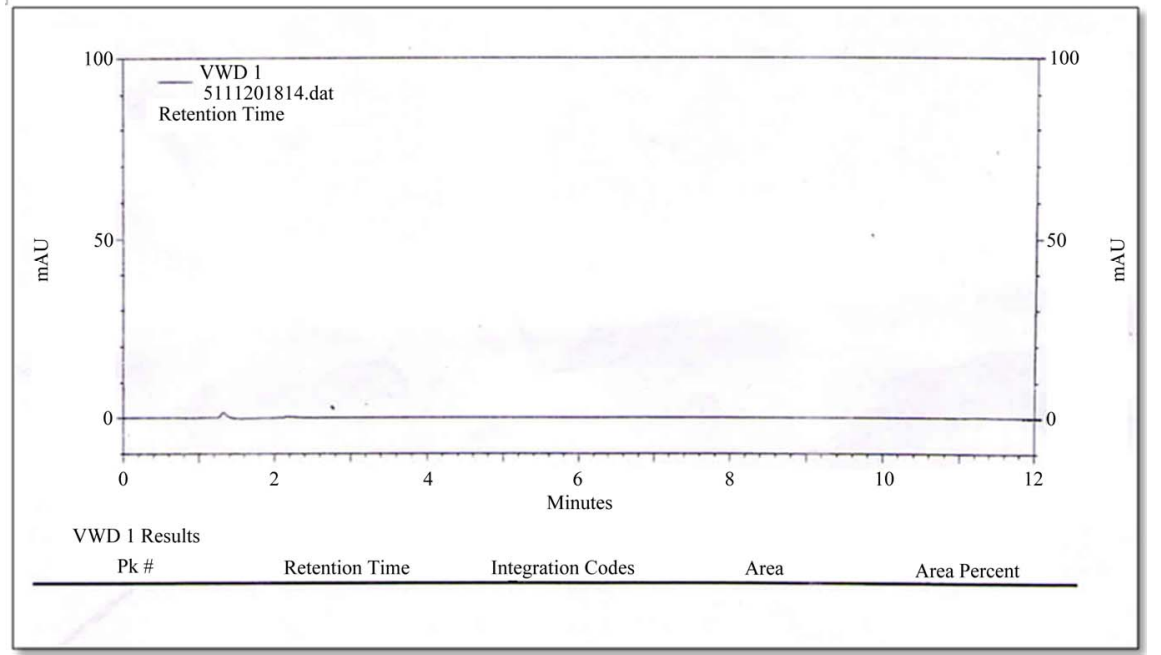

Figure 2. Chromatorgram for blank of Alfuzosin HCI by RP-HPLC method.

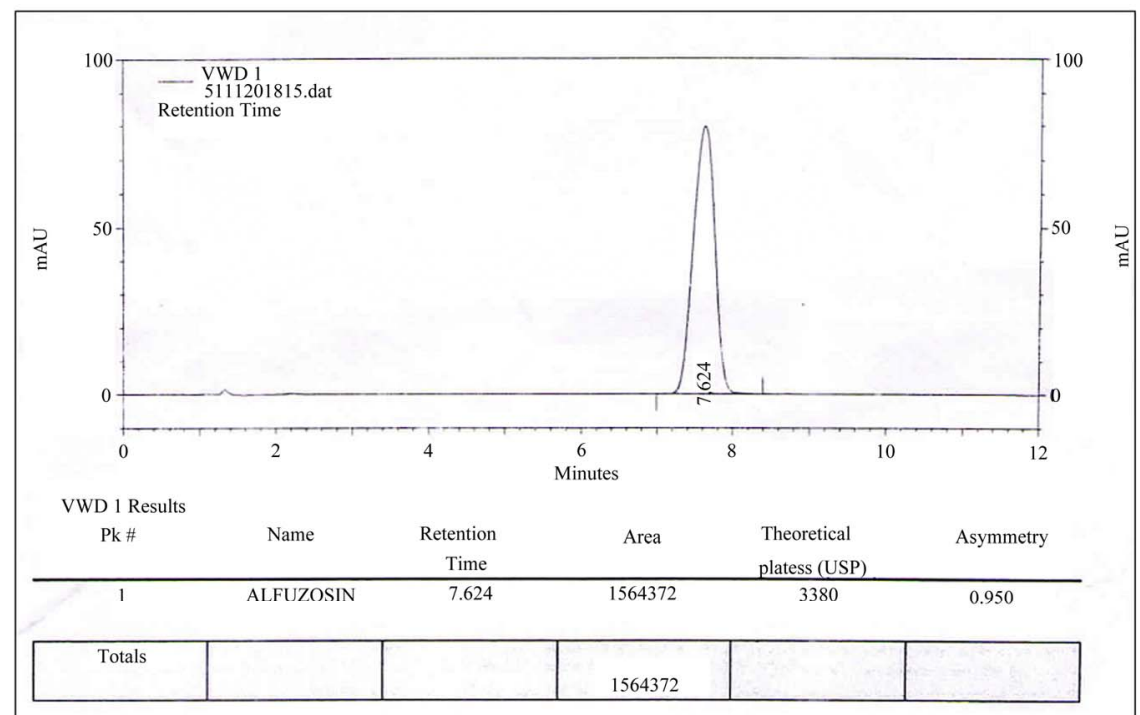

Figure 3. Chromatorgram for system suitability of Alfuzosin HCl by RP-HPLC method. 


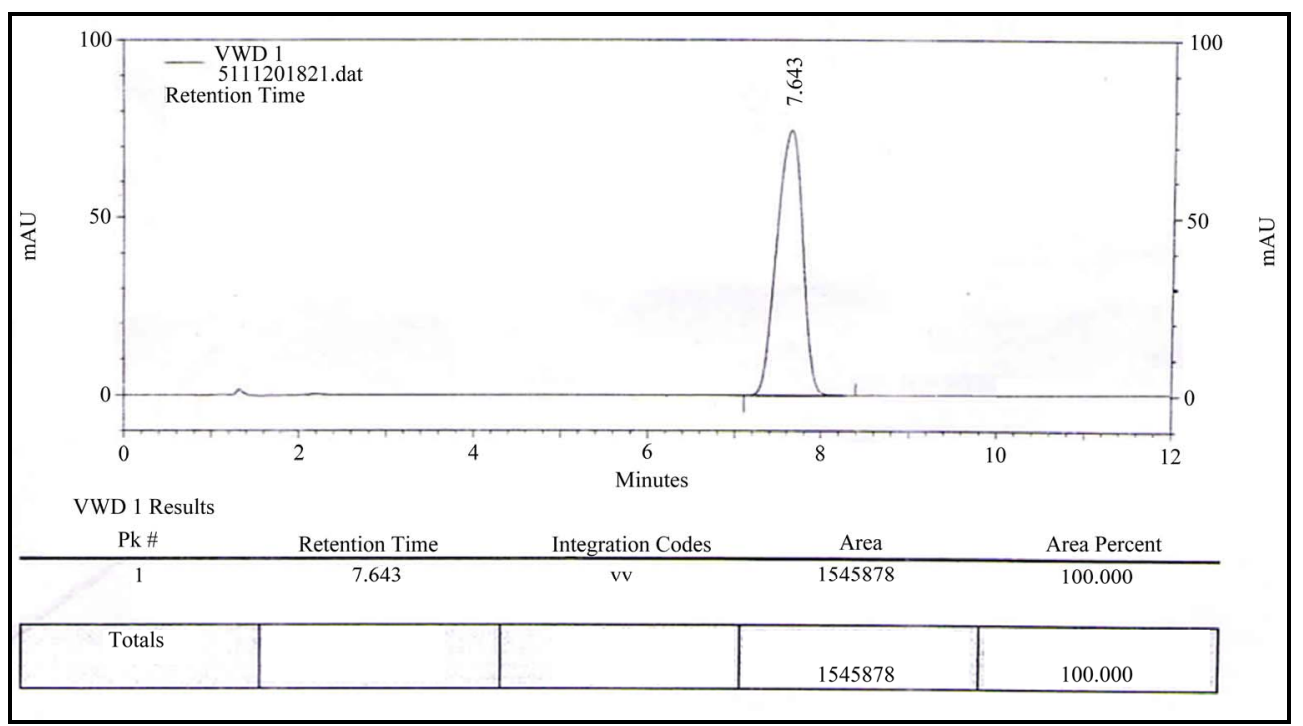

Figure 4. Chromatorgram of Alfuzosin HCl for sample by RP-HPLC method.

prepared as per procedure and was injected five times into the HPLC system. The system suitability parameters were evaluated from standard chromatograms obtained by calculating the RSD of retention times, tailing factor, theoretical plates and peak areas from five replicate injections (Table 1).

\subsection{Specificity}

Peak purity of Alfuzosin hydrochloride was assessed to evaluate the specificity of the method. The sample and standard chromatograms were scanned at three different levels, i.e. peak start (S), peak apex (M) and peak end (E) positions. The specificity of the RP-HPLC method was determined by comparison of the chromatogram of standard and sample solution.

\subsection{Linearity of the Calibration Line}

From the stock solution of Alfuzosin hydrochloride, prepare the dilutions over concentration range of $80-120$ $\mu \mathrm{g} / \mathrm{ml}$. These solutions were injected in to HPLC system as per test procedure and recorded the area under curve (Table 2) A calibration curve was plotted for concentration verses peak area and was shown in the Figure 5.

\section{Precision}

\subsection{System Precision}

Five samples of $100 \mu \mathrm{g} / \mathrm{ml}$ solutions were prepared and injected into the HPLC system as per test procedure (Table 3).

\subsection{Method Precision}

Six samples of $100 \mu \mathrm{g} / \mathrm{ml}$ of Alfuzosin hydrochloride
Table 1. System suitability data of Alfuzosin HCl by RPHPLC method.

\begin{tabular}{ccc}
\hline Parameter & Observed value & Acceptance criteria \\
\hline Peak area $\left(\mathrm{cm}^{2}\right)$ & $1,564,372$ & - \\
Retention time $(\mathrm{min})$ & 7.624 & - \\
Asymmetry & 0.950 & - \\
Tailing factor $\left(\mathrm{T}_{\mathrm{f}}\right)$ & 0.95 & NMT 2\% \\
Theoretical plates $(\mathrm{N})$ & 3380 & NLT 2000 \\
\hline
\end{tabular}

Table 2. Linearity of Alfuzosin HCl by RP-HPLC method.

\begin{tabular}{cc}
\hline Concentration $(\mu \mathrm{g} / \mathrm{ml})$ & Area $\left(\mathrm{cm}^{2}\right)$ \\
\hline 0 & 0 \\
80 & $1,536,654$ \\
90 & $1,698,736$ \\
100 & $1,920,818$ \\
110 & $2,092,899$ \\
120 & $2,299,981$ \\
\hline
\end{tabular}

solutions were prepared and injected into the HPLC system as per test procedure (Table 3).

\subsection{Intra-Day Precision}

Intraday precision of test method is demonstrated by three injections of the same batch (same concentration) of samples at initial, 24 and 48 hrs (Table 4).

\subsection{Inter-Day Precision}

Inter-day precision of test method is demonstrated by three injections of the same batch (same concentration) 


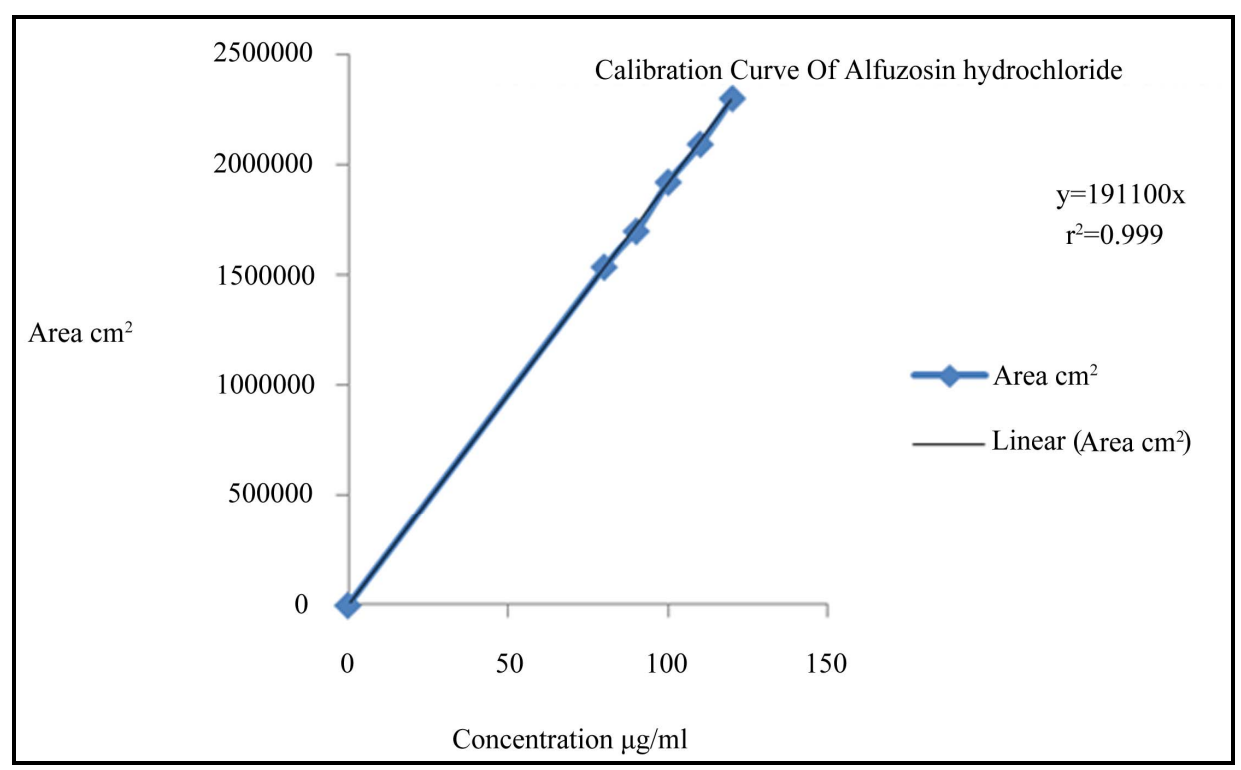

Figure 5. Linearity curve of Alfuzosin HCl by RP-HPLC method.

of samples on three successive days (Table 4).

\subsection{Accuracy}

The accuracy of the method was assessed by determination of the recovery of Alfuzosin hydrochloride at three levels of concentrations $(80 \%, 100 \%$ and $120 \%)$ by addition of known amount of standard to the placebo. Solutions were prepared in triplicate and analyzed. This procedure was repeated for three consecutive days. Calibration curves to estimate the concentration of drug per peak were measured daily on the same column. The accuracy was determined and expressed as percentage recovery (Table 5).

\section{Robustness}

The effect of deliberate variation in method parameters like the composition of mobile phase, temperature and flow rate were evaluated in this study. The effect of these changes on $t_{R}$ and peak area was evaluated by calculating the relative standard deviations (RSD) for each parameter.

\subsection{Effect of Variation of Mobile Phase Composition}

A study was conducted to determine the effect of variation in mobile phase ratio by changing the ratio of mobile phase i.e. Tetrahydrofuran: Acetonitrile: Buffer from $1: 20: 80$ to $1: 25: 75$ and $1: 15: 85$. Standard solution was prepared and injected into the HPLC system. The retention time values were measured and are given in Table 6.

\subsection{Effect of Variation of Temperature}

A study was conducted to determine the effect of variation
Table 3. Method and system precision.

\begin{tabular}{ccccc}
\hline Parameters & \multicolumn{2}{c}{ Method precision } & \multicolumn{2}{c}{ System precision } \\
\hline Injection number & $\begin{array}{c}\text { Retention } \\
\text { time }(\mathrm{min})\end{array}$ & $\begin{array}{c}\text { Area } \\
\left(\mathrm{cm}^{2}\right)\end{array}$ & $\begin{array}{c}\text { Retention } \\
\text { time }(\mathrm{min})\end{array}$ & Area $\left(\mathrm{cm}^{2}\right)$ \\
\hline 1 & 7.638 & $1,565,906$ & 7.634 & $1,545,456$ \\
2 & 7.624 & $1,564,372$ & 7.624 & $1,564,372$ \\
3 & 7.643 & $1,545,878$ & 7.636 & $1,556,482$ \\
4 & 7.634 & $1,563,510$ & 7.638 & $1,566,255$ \\
5 & 7.638 & $1,563,777$ & 7.635 & $1,563,518$ \\
6 & 7.638 & $1,566,255$ & - & \\
Avg & 7.64 & 1561616.33 & 7.633 & 1559216.6 \\
SD & 0.01 & 7790.53 & 0.01 & 8535.97 \\
RSD & 0.08 & 0.5 & 0.07 & 0.55 \\
\hline
\end{tabular}

Table 4. Intraday and inter-day precision data of ALH by RP-HPLC method.

\begin{tabular}{|c|c|c|c|c|c|}
\hline \multicolumn{2}{|c|}{ Parameters } & \multicolumn{2}{|c|}{ Intra-day precision } & \multicolumn{2}{|c|}{ Inter-day precision } \\
\hline $\begin{array}{l}\text { Injection } \\
\text { number }\end{array}$ & $\begin{array}{c}\text { Duration } \\
\text { hours }\end{array}$ & $\begin{array}{l}\text { Retention } \\
\text { time (min) }\end{array}$ & Area $\left(\mathrm{cm}^{2}\right)$ & $\begin{array}{l}\text { Retention } \\
\text { time (min) }\end{array}$ & Area $\left(\mathrm{cm}^{2}\right)$ \\
\hline 1 & 0 & 7.638 & $1,555,878$ & 7.637 & $1,555,906$ \\
\hline 2 & 24 & 7.646 & $1,571,819$ & 7.646 & $1,568,211$ \\
\hline 3 & 48 & 7.652 & $1,567,674$ & 7.649 & $1,592,354$ \\
\hline \multicolumn{2}{|c|}{ Avg } & 7.65 & $1,565,124$ & 7.64 & $1,572,157$ \\
\hline \multicolumn{2}{|c|}{ SD } & 0.01 & 8270.85 & 0.01 & 18541.64 \\
\hline \multicolumn{2}{|c|}{ RSD } & 0.09 & 0.53 & 0.08 & 1.18 \\
\hline
\end{tabular}


Table 5. Accuracy data of ALH by RP-HPLC method.

\begin{tabular}{cccccc}
\hline $\begin{array}{c}\text { Sample } \\
\text { id }\end{array}$ & \multicolumn{1}{c}{ Concentration } & $\begin{array}{c}\text { Percentage } \\
\text { recovery }\end{array}$ & $\begin{array}{c}\text { Mean } \\
\text { percentage } \\
\text { recovery }\end{array}$ & $\begin{array}{c}\text { Standard } \\
\text { deviation }\end{array}$ & $\begin{array}{c}\text { Relative } \\
\text { standard } \\
\text { deviation }\end{array}$ \\
\hline 1 & $80 \%$ & 100.32 & & & \\
2 & $80 \%$ & 100.19 & 100.20 & 0.12 & 0.115 \\
3 & $80 \%$ & 100.09 & & & \\
4 & $100 \%$ & 100.14 & & & \\
5 & $100 \%$ & 100.23 & 100.26 & 0.14 & 0.143 \\
6 & $100 \%$ & 100.42 & & & \\
7 & $120 \%$ & 100.32 & & & \\
8 & $120 \%$ & 100.07 & 100.29 & 0.20 & 0.201 \\
9 & $120 \%$ & 100.47 & & & \\
\hline
\end{tabular}

Table 6. Effect of variation.

\begin{tabular}{cccccc}
\hline $\begin{array}{c}\text { System } \\
\text { suitability } \\
\text { parameter }\end{array}$ & $\begin{array}{c}\text { Mobile } \\
\text { phase }\end{array}$ & $\begin{array}{c}\text { valverved } \\
\text { valve }\end{array}$ & Temperature & $\begin{array}{c}\text { Observed } \\
\text { valve }\end{array}$ & $\begin{array}{c}\text { Acceptance } \\
\text { criteria }\end{array}$ \\
\hline $\begin{array}{c}\text { Asymmetry } \\
\text { factor of }\end{array}$ & $15 \%$ & 0.932 & $30^{\circ} \mathrm{C}$ & 0.968 & \\
$\begin{array}{c}\text { ALH peak in } \\
\text { standard }\end{array}$ & $30 \%$ & 0.988 & $28^{\circ} \mathrm{C}$ & 0.998 & $0.5-2.0$ \\
\hline
\end{tabular}

in temperature. Standard solution was prepared and injected into the HPLC system by keeping temperature $30^{\circ} \mathrm{C}, 28^{\circ} \mathrm{C}$ and $32^{\circ} \mathrm{C}$. The effect of variation of temperature was evaluated and the results were discussed in the Table 6.

\subsection{Ruggedness}

Ruggedness is the degree of reproducibility of the results obtained under a variety of conditions. It is checked that the results are reproducible under differences in conditions, analysts and instruments. It was tested on the second HPLC column of the same type by determining linearity, precision and accuracy. Linearity was performed at six concentration points for ALH in the concentration range from $80-120 \mu \mathrm{g} / \mathrm{ml}$. The regression equation was $y=19101 x$ and the correlation coefficient was 0.9988 . Intra-day precision and accuracy were determined by measuring three series of quality control samples. Relative standard deviations at all three concentrations studied for ALH was less than 2\%. The relative error ranged from $0.9 \%$ to $1.0 \%$ of the nominal concentrations of the ALH. As it can be seen, the results of this assessment are very similar to those obtained by the previous ALH on the first investigation column. This means that this HPLC method for the determination of ALH in bulk tablet samples is rugged. The Chromatograms were shown in Fig- ures 6 and 7 by different analysts.

\subsection{Limit of Detection (LOD)}

The detection limit of an individual analytical procedure is the lowest amount of analyte in a sample that can be detected but not necessarily quantitated as an exact value.

\subsection{Limit of Quantification (LOQ)}

The quantitation limit of an individual analytical procedure is the lowest amount of analyte in a sample that can be quantitatively determined with suitable precision and accuracy. The quantitation limit is a parameter of quantitative assays for low levels of compounds in sample matrices, and is used particularly for the determination of impurities and/or degradation products.

\subsection{Assay}

Assay of tablet dosage form was carried by injecting sample corresponding to equivalent weight of ALH into HPLC system. The percent purity was found out using regression analysis. Recovery studies were carried out at $80 \%, 100 \%$ and $120 \%$. The percentage recovery was shown in Table 7.

\section{Result and Discussion}

\subsection{Chromatographic Conditions for RP HPLC Method}

The RP-HPLC technique was employed in the present investigation for Alfuzosin hydrochloride in bulk and tablet dosage form. Careful evaluation of various parameters influencing analysis is an important aspect for the development of analytical method. In order to establish RP-HPLC method, the parameters studies are discussed as follows.

1) Proper selection of the method depends upon the nature of the sample, molecular weight and solubility. The selected drug, Alfuzosin hydrochloride for the present study was polar. Polar compounds can be separated by reverse phase chromatography. Reverse phase chromatographic technique was selected for initial separations from the knowledge of properties of the compound. $\mathrm{C}_{18}$ column was chosen as stationary phase and a mixture of Tetrahydrofuran, Acetonitrile and buffer (pH 3.5) was used as mobile phase. Then it was preceded with different ratios of mobile phase;

2) During selection and optimization of the mobile phase it was observed that the retention time of Alfuzosin hydrochloride is decreased with increased in the proportion of organic modifier like acetonitrile in the mobile phase. The sharpness of the peak is achieved with increasing the proportion of acetonitrile whereas the increased 


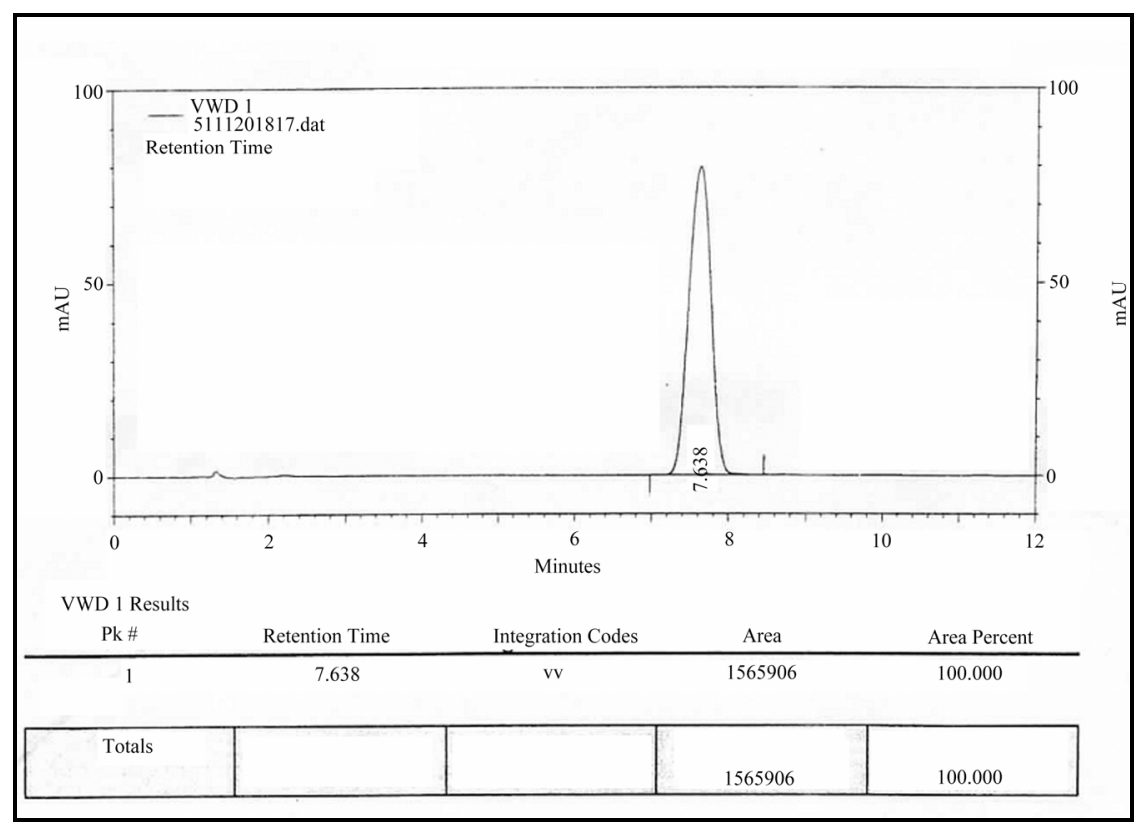

Figure 6. RP-HPLC chromatogram of ALH performed by analyst 1.

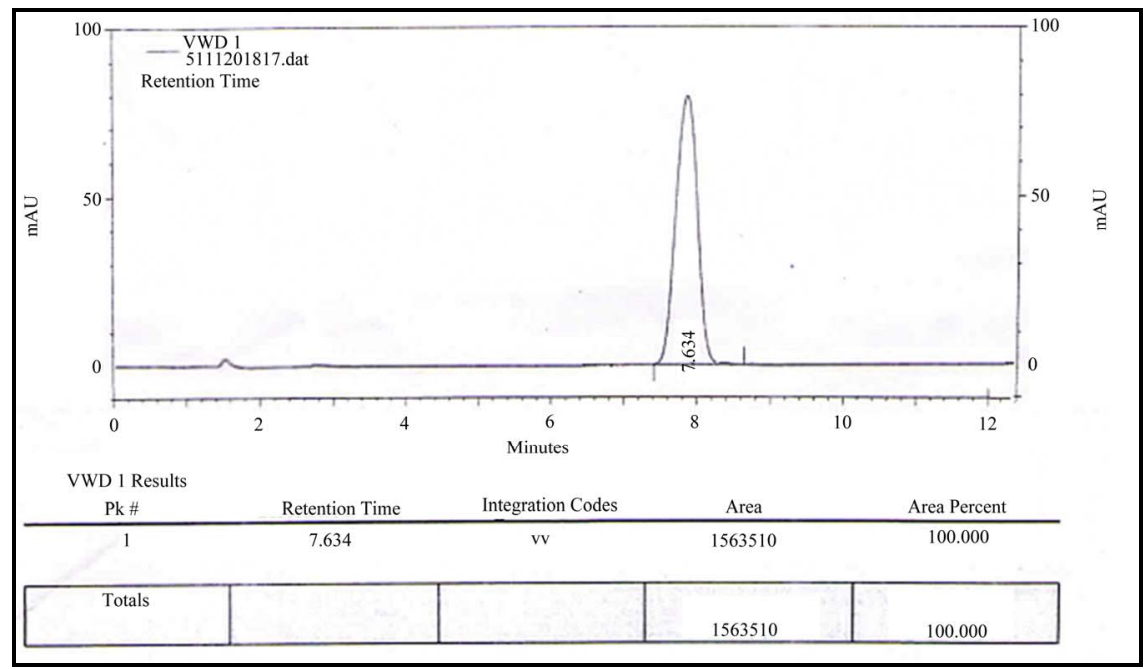

Figure 7. RP-HPLC chromatogram of ALH performed by analyst 2.

proportion of aqueous resulted in broadening of the peak. Thus mobile phase comprising of Tetrahydrofuran, Acetonitrile and buffer (PH 3.5) (1:20:80) was confirmed. The selection of the wavelength was based on the $\lambda$ max obtained by scanning of standard laboratory mixture in mobile phase and was found to be $254 \mathrm{~nm}$. This system gave good resolution and optimum retention time with appropriate tailing factor $(<2)$. The mean values of system suitability test result are depicted above. After establishing the chromatographic conditions, standard laboratory mixture was prepared and analysed by following procedure described under experimental and results. As the method give accurate, reliable results and therefore was extended for estimation of drugs in tablet formulation.

\subsection{Method Validation}

Validation of these of these methods was performed as per the ICH guidelines for these following parameters.

\subsubsection{Stability and Suitability}

The solution of Alfuzosin hydrochloride was found to be stable for one day at room temperature.

From the system suitability studies it was observed that all the parameters were within limits. The RSD for the retention times of principal peak from 5 replicate injections of each Standard solution was observed not more than $2.0 \%$, the tailing factor $\left(\mathrm{T}_{\mathrm{f}}\right)$ for the Alfuzosin Hydrochloride peaks was observed not more than $2 \%$. 
and the number of theoretical plates $(\mathrm{N})$ for the Alfuzosin peaks was observed not less than 2000 (Table 1). Hence it was concluded that the Instrument, Reagents and Column were suitable to perform the assay.

\subsubsection{Specificity}

Studies show that there is no interference of peak from the component showing retention time for Alfuzosin $\mathrm{HCl}$ $7.632 \mathrm{~min}$ (Table 1).

\subsubsection{Linearity}

The linearity range was found to be of $80-120 \mu \mathrm{g} / \mathrm{ml}$ as shown in Tables 2 and 5. The regression equation and correlation coefficient $(r)$ obtained by least square regression method were 0.998 . The linearity of the calibration graph and conformity of RP-HPLC value to Beer's Law were proven by the high correlation coefficients $\left(r^{2}\right.$ $=0.999$ ) for the regression equation, $y=19100 x$.

\subsubsection{Precision}

Replicate estimation of tablet analysed by the proposed method has yielded quite consistent result indicating repeatability of method. Study showed \pm S.D. $<2$. The Relative Standard Deviation (RSD) of results for system and method acceptance criteria were observed not more than $2.0 \%$ as shown in Table 2. Similarly the relative standard deviation of three replicate injections for intraday and inter day precision were not more than $2.0 \%$ (Table 4).

\subsubsection{Accuracy}

Accuracy of the proposed method was ascertained from the recovery studies by standard addition method. The mean \% recovery of the Alfuzosin hydrochloride at each level was observed not less than $97.0 \%$ and not more than $103.0 \%$. The results were observed good recovery within limits (98\% - 102\%) as discussed in Table 5.

\subsubsection{Robustness}

Table 6 shows that RSD and asymmetry factor for ALH standard was found to be within a limit of 0.5 to 2.0 for variation in composition of mobile phase and temperature. Thus, the proposed method is robust for small variations in the test method.

\subsubsection{Ruggedness}

Studies were carried out only for the two different parameters like different time, different days and different analyst. Results of estimation by proposed method are very much similar under variety of conditions as shown in Figures 6 and 7. This study signifies the ruggedness of the method under varying condition of its performance.

\subsubsection{Limit of Detection and Limit of Quantification (LOD and LOQ)}

On the basis of response and slope of the regression equation, the LOD and LOQ for this method were found to be 0.3212 and 0.5764 respectively.

\subsubsection{Assay}

Assay results show excellent label claim of $99.67 \%$ 99.98\% for ALH (Table 7).

\section{Conclusion}

A new, simple, quick, precise and accurate method based on HPLC has been developed with short analysis time using the mobile phase of Tetrahydrofuran: Acetonitrile: buffer $(1: 20: 80) \% \mathrm{v} / \mathrm{v} / \mathrm{v}$. The method was successfully validated for stability, specificity, linearity, precision,

Table 7. Assay of formulation of ALH by RP-HPLC.

\begin{tabular}{|c|c|c|c|c|c|}
\hline Sample id & Concentration & Percentage recovery & $\begin{array}{c}\text { Mean percentage } \\
\text { recovery }\end{array}$ & Standard deviation & $\begin{array}{c}\text { Relative standard } \\
\text { deviation }\end{array}$ \\
\hline 1 & $80 \%$ & 100.02 & & & \\
\hline 2 & $80 \%$ & 99.85 & 99.98 & 0.12021 & 0.12029 \\
\hline 3 & $80 \%$ & 100.08 & & & \\
\hline 4 & $100 \%$ & 99.71 & & & \\
\hline 5 & $100 \%$ & 99.88 & 99.85 & 0.13192 & 0.13228 \\
\hline 6 & $100 \%$ & 99.97 & & & \\
\hline 7 & $120 \%$ & 99.71 & & & \\
\hline 8 & $120 \%$ & 99.52 & 99.67 & 0.14435 & 0.14487 \\
\hline 9 & $120 \%$ & 99.79 & & & \\
\hline
\end{tabular}


accuracy, robustness and ruggedness. Assay result shows excellent label claim of $99.67 \%$ - 99.98\% for ALH. Thus, the proposed RP-HPLC method is economic and suitable for quality control of Alfuzosin $\mathrm{HCl}$ in bulk, fixed-dose combination tablets and dissolution studies.

\section{Acknowledgements}

The authors are thankful to the Principal, Dr. S. S. Angadi and the Management, Yash Institute Of Pharmacy for providing laboratory facilities and authors greatly acknowledge, Wockhardt Pharma Pvt. Ltd., Aurangabad (Maharashtra) for providing the gift sample of Alfuzosin hydrochloride.

\section{REFERENCES}

[1] D. Yu, et al., "Research Highlights," Prostate News Prostate Cancer and Prostatic Diseases, Vol. 9, 2006, pp. 2-5.

[2] S. A. Mc Neill, T. B. Hargreave, C. Geffriaud-Ricouard, J. Santoni and C. G. Roehrborn, "Postvoid Residual Urine in Patients with Lower Urinary Tract Symptoms Suggestive of Benign Prostatic Hyperplasia: Pooled Analysis of Eleven Controlled Studies with Alfuzosin," Urology, Vol. 57, No. 3, 2001, pp. 459-465.

[3] M. Vamsi Krishna and D. Gowri Sankar, "Optimization and Validation of Quantitative Spectrophotometric Methods for the Determination of Alfuzosin in Pharmaceutical Formulations," E-Journal of Chemistry, Vol. 4, No. 3, 2007, pp. 397-407.

[4] M. Vamsi Krishna and D. Gowri Sankar, "New Diazo Coupling Reactions for Visible Spectrometric Determination of Alfuzosin in Pharmaceutical Preparations," $E$ Journal of Chemistry, Vol. 4, No. 4, 2007, pp. 496-501.

[5] M. Vamsi Krishna and D. Gowri Sankar, "Oxidative Coupling, Complex Formation and Internal Salt Formation Reactions for Visible Spectrophotometric Determination of Alfuzosin Hydrochloride in Pharmaceutical Formulations," The Pharma Review, June-July 2007, pp. 143-145.

[6] A. Safwan, C. Fawaz and B. Roula, "Spectrophotometric determination of Alfuzosin Hydrochloride in Pharmaceutical Preparations with Some Sulphonepthelein Dyes," International Journal of Biomedical Science, Vol. 2, No. 3, 2006, pp. 273-278.

[7] B. M. Ishaq, K. V. Prakash, C. H. Kumar, G. U. Rani and P. Ramakrishna, "Colorimetric Determination of Alfuzosin $\mathrm{HCl}$ in Pharmaceutical Formulations," Journal of Pharmacy Research, Vol. 4, No. 1, 2011, pp. 226-228.

[8] B. Uslu, "Voltammetric Analysis of Alfuzosin $\mathrm{HCl}$ in Pharmaceuticals, Human Serum and Simulated Gastric Juice," Electroanalysis, Vol. 14, No. 12, 1990, pp. 866870.

[9] A. Rouchouse, M. Manoha, A. Durand and J. P. Thenot, "Direct High Performance Liquid Chromatographic Determination of the Enantiomers of Alfuzosin in Plasma on a Second-Generation A1-Acid Glycoprotein Chiral Stationary Phase," Journal of Chromatography A, Vol. 506, 1990, pp. 601-610.
[10] P. Guinebault, M. Broquaire, C. Colafranceschi and J. P. Thénot, "High-Performance Liquid Chromatographic Determination of Alfuzosin in Biological Fluids with Fluorimetric Detection and Large-Volume Injection," Journal of Separation Science, Vol. 29, No. 15, 2011, pp. 23032309.

[11] K. S. B. Kumar, V. A. Ranjani and D. Sathyavathi, "New RP-HPLC Method Development and Validation for Assay of Alfuzosin Hydrochloride in Tablet Dosage Form," International Journal of Pharmacy and Pharmaceutical Sciences, Vol. 2, No. 4, 2010, pp. 90-92.

[12] G. Mani, S. Uppatyay, R. Tivari, K. Kalliappan, R. Govindasamy, S. Gangully and S. Thangavel, "Quantitation of Alfuzosin Hydrochloride in Pharmaceutical Formulations by RP-HPLC," Pakistan Journal of Pharmaceutical Sciences, Vol. 22, No. 3, 2009, pp. 263-266.

[13] S. A. Raju, A. B. Karadi and S. Manjunath, "Reverse Phase HPLC Method for the Analysis of Alfuzosin Hydrochloride in Pharmaceutical Dosage Forms," International Journal of Chemical Sciences, Vol. 6, No. 1, 2008, pp. 399-404.

[14] G. Carlucci, E. Di Giuseppe and P. Mazzeo, "Determination of Alfuzosin in Human Plasma by High-Performance Liquid Chromatography with Column-Switching," Journal Liquid Chromatography and Related Technologies, Vol. 17, No. 18, 1994, pp. 3989-3997. doi: $10.1080 / 10826079408016168$

[15] J. L. Wiesner, F. C. W. Sutherland, G. H. Van Essen, H. K. L. Hundt, K. J. Swart and F. Hundt, "Selective, Sensitive and Rapid Liquid Chromatography-Tandem Mass Spectrometry Method for the Determination of Alfuzosin in Human Plasma," Journal of Chromatography B, Vol. 788, No. 2, 2003, pp. 361-368. doi:10.1016/S1570-0232(03)00064-3

[16] D. B. Patel and N. J. Patel, "Development and Validation of Reverse Phase High Performance Liquid Chromatography and High Performance Thin Layer Chromatography Methods for Estimation of Alfuzosin Hydrochloride in Bulk and in Pharmaceutical Formulations," International Journal of ChemTech Research, Vol. 1, No. 4, 2009, pp. 985-990.

[17] A. S. Fayed, M. A. Shehata, N. Y. Hassan and S. A. El Weshahy, "Validated HPLC and HPTLC Stability-Indicating Methods for Determination of Alfuzosin Hydrochloride in Bulk Powder and Pharmaceutical Formulations," Journal Of Separation Science, Vol. 29, No. 18, 2006, pp. 2716-2724. doi:10.1002/jssc. 200600220

[18] S. S. Deshmukh, S. S. Havele, V. V. Musale and S. R. Dhaneshwar, "Development and Validation of RP-HPLC Method for Simultaneous Estimation of Alfuzosin Hydrochloride and Dutasteride in Pharmaceutical Dosage Form," Scholars Research Library, Vol. 2, No. 6, 2010, pp. 342-349.

[19] Ch. A. Varshini, K. S. Kumari, S. Sushma and K. Prakash, "Development And Validation Of RP-HPLC Method For Simultaneous Estimation Of Alfuzosin Hydrochloride and Dutasteride in Bulk and Pharmaceutical Dosage Form," Inventi Rapid: Pharm Analysis \& Quality Assurance, Vol. 2012, No. 4, 2012. 
[20] K. S. B. Kumar, V. A. Ranjani and D. Sathyavathi, "New RP-HPLC Method Development and Validation for Assay of Alfuzosin Hydrochloride in Tablet Dosage Form,"
International Journal of Pharmacy and Pharmaceutical Sciences, Vol. 2, No. 4, 2010, pp. 90-92. 